\title{
Synergy Assessment for Plant Growth by Independent Joint Action Theory
}

\author{
Zhengyu Huang and Kimberly Ann Falco \\ Valent BioSciences, LLC, 1910 Innovation Way, Suite 100, Libertyville, \\ IL 60048
}

Additional index words. Abbott's formula, Bliss formula, Bliss theory, gibberellic acid, mixture synergy, plant growth regulator, $S$-abscisic acid, synergism, synergy factor

\begin{abstract}
Calculating the predicted biological efficacy of a mixture and determining the significance of the difference between the predicted efficacy and the measured efficacy of that mixture are fundamental when assessing the synergy of mixtures. The Independent Joint Action theory and Bliss's formula are well-known and widely accepted for predicting pesticide mixture effects that are expressed in terms of percent mortality. Bliss's formula, however, is not applicable to growth-affecting components, such as plant growth regulators. Therefore, there is an unmet need of critical importance: an appropriate method for assessing synergy of growth-affecting mixtures needs to be identified within the scientific community. The formula, $G_{(1+2 \bullet n)}=G_{1} G_{2} \ldots G_{n} /\left(G_{C T L}\right)^{n-1}$, which was derived from the Independent Joint Action theory, is presented for calculating the predicted efficacy for mixtures of growth-affecting components that either promote or inhibit growth. Its application is demonstrated by analyzing data from a greenhouse assay in which a mixture of $S$-abscisic acid and gibberellic acid was used to promote the growth of corn seedlings.
\end{abstract}

Plant responses to plant growth regulators (PGRs) often include increases in size, biomass, and yield, thereby differentiating them from other pesticides (e.g., herbicides, fungicides, insecticides), which often include damage, inhibition, or lethality to their targeted organisms (Pohanish, 2014). Such responses may be amplified or diminished when PGR compounds are applied as mixtures. Existing methods and formulas based on proportions or percent damage, inhibition, or lethality cannot be directly and readily applied to PGR mixtures for the aforementioned "increase" responses; therefore, a different approach is required.

The methods used to quantify the predicted effect of a mixture on biological systems have been studied in great depth and are considered paramount for accurately assessing synergy. Various methods of analyzing the effects of mixtures have been used, debated, and repeatedly reviewed over the past century (Cedergreen et al., 2014; Foucquier and Guedj, 2015). Two distinct, well-known, and widely accepted theories for predicting mixture effects were proposed by Loewe and Muischnek (1926) and Bliss (1939). Loewe

Received for publication 27 Jan. 2021 Accepted for publication 26 Feb. 2021

Published online 26 April 2021.

We appreciate the feedback, input, and support provided by Warren Shafer, Greg Venburg, Mark Beach, Peter Petracek, Marci Surpin, and Dale Wilson at Valent BioSciences LLC, as well as the assistance with statistical analysis provided by Xiangyao $\mathrm{Su}$ at Astex Pharmaceuticals Inc.

K.A.F. is the corresponding author. E-mail: kfalc@valent.com

This is an open access article distributed under the CC BY-NC-ND license (https://creativecommons. org/licenses/by-nc-nd/4.0/). and Muischnek's theory assumed that all active components in a mixture act on the same biological target but with different potencies to achieve an equivalent result; therefore, one component could be substituted at a constant proportion to the other. This concept has been given many titles, such as Loewe Additivity, Dose Addition, the Additive Dose Model (ADM), Concentration Addition (CA), or Similar Joint Action, depending on the authors and their research areas (Cedergreen et al., 2013). Both isobolograms and combination indices exemplify approaches that were developed based on Loewe and Muischnek's theory (Gisi, 1996; Kull et al., 1961; Roell et al., 2017; Tammes, 1964; Voorspuij and Nass, 1957). Loewe and Muischnek's theory is a topic that continues to be actively studied and reviewed by researchers in many fields, including pharmacology (Chou, 2006; Foucquier and Guedj, 2015; Roell et al., 2017; Zhao et al., 2010).

Alternatively, Bliss (1939) proposed the theory of Independent Joint Action using insects as a model organism for which mortality was the response to the components of a mixture. The Independent Joint Action theory assumes the active components in a mixture function independently with different modes of action. Therefore, the component effects of a mixture can be predicted by the dosage-mortality of each component when applied alone. Bliss's formula to predict the effect of a twocomponent mixture is presented as follows:

$$
\begin{gathered}
\mathrm{P}_{(\mathrm{A}+\mathrm{B})}=\mathrm{P}_{\mathrm{A}}+\left(1-\mathrm{P}_{\mathrm{A}}\right) \mathrm{P}_{\mathrm{B}} \\
\text { or, } \mathrm{P}_{(\mathrm{A}+\mathrm{B})}=\mathrm{P}_{\mathrm{A}}+\mathrm{P}_{\mathrm{B}}-\mathrm{P}_{\mathrm{A}} \mathrm{P}_{\mathrm{B}}
\end{gathered}
$$

where $\mathrm{P}_{(\mathrm{A}+\mathrm{B})}$ signifies the predicted effect as the proportion killed as a result of the mixture of components $\mathrm{A}$ and $\mathrm{B}$ at rates $a$ and $b$, respectively; $\mathrm{P}_{\mathrm{A}}$ and $\mathrm{P}_{\mathrm{B}}$ indicate the proportion killed as a result of component $\mathrm{A}$ at rate $a$ and component $\mathrm{B}$ at rate $b$ when each is applied alone (Bliss, 1939). Additionally, (1 $\left.\mathrm{P}_{\mathrm{A}}\right) \mathrm{P}_{\mathrm{B}}$ can be interpreted as the action of component $\mathrm{B}$ when acting on what survived the action of component A. As Bliss (1939) pointed out, the aforementioned formula, after transformation, is tantamount to Abbott's formula (Abbott, 1925), which was first introduced to compute the percent control of insects as an adjustment to exclude natural insect mortality during experiments.

Similar to Loewe and Muscinek's theory, the Independent Joint Action theory has been assigned many names, including Bliss Independence, Independent Action, Multiplicative Survival Model (MSM), Response Multiplication, Response Addition, and Effect Addition (Bliss, 1939; Cedergreen et al., 2014; Colby, 1967; Gisi, 1989, 1996; Levy et al., 1986; Morse, 1978; Nash, 1981; Zhao, et al., 2014). Bliss's formula is widely applicable and frequently used to assess component interactions by determining the predicted effect of mixtures tested during agricultural experiments (e.g., insecticides, herbicides, and fungicides) and environmental research studies (e.g., toxicity assessments) in which effects are expressed as proportions or in terms of percent damage, inhibition, or lethality (Altenburger, et al., 2013; Foucquier and Guedj, 2015; U.S. Environmental Protection Agency, 2000). Bliss's Independent Joint Action theory is also regarded as a particularly important alternative to Loewe Additivity in pharmacological research (Zhao et al., 2014). Despite its wide acceptance and frequent use, Bliss's formula has limitations. It is limited to proportional data types that range from 0 to 1 (or percentage data ranging from $0 \%$ to $100 \%$ ). Additionally, Bliss's formula cannot accommodate nonproportional data, such as growth or increases in size or weight (Foucquier and Guedj, 2015). Because Bliss's formula is not designed for computing predicted nondestructive effects, many responses to plant growth regulators and stimulants cannot be used in Bliss's formula to assess synergy. Therefore, a formula other than Bliss's is needed for computing predicted effects on growth for mixtures of plant growth regulators or combinations of growth-affecting components/factors such as fertilizers, temperature, moisture, and plant growth-promoting microbes (PGPM).

A formula derived from Bliss's Independent Joint Action theory is presented here. A single data set from various PGR mixture studies was selected and used solely for demonstrating the application of the proposed formula. During the selected experiment, a mixture of plant growth regulators $(S$-abscisic acid and gibberellic acid) was tested. Although $S$-abscisic acid ( $S$-ABA) can have an inhibitory growth effect, gibberellins are known to stimulate cell elongation (Basra, 2000; Fletcher et al., 2000; Kaur et al., 2018). Accordingly, S-ABA and gibberellic acids arguably belong to different classes of plant growth regulators. 


\section{Materials and Methods}

Formula for computing the predicted growth. When assessing a two-component mixture, the mathematical model for the difference in growth when compared with the control is derived from the Independent Joint Action theory and is expressed as follows:

$$
\Delta \mathrm{G}_{(\mathrm{A}+\mathrm{B})}=\Delta \mathrm{G}_{\mathrm{A}}+\Delta \mathrm{G}_{\mathrm{B}}+\Delta \mathrm{G}_{\mathrm{AB}}
$$

where $\Delta \mathrm{G}_{(\mathrm{A}+\mathrm{B})}$ is the difference in growth (when compared with the control) resulting from the two-component mixture applied at rate $a$ for component $\mathrm{A}$ and at rate $b$ for component $\mathrm{B} ; \Delta \mathrm{G}_{\mathrm{A}}$ is the difference in growth (when compared with the control) resulting from component A applied at rate $a ; \Delta \mathrm{G}_{\mathrm{B}}$ is the difference in growth (when compared with the control) resulting from component $\mathrm{B}$ applied at rate $b ; \Delta \mathrm{G}_{\mathrm{AB}}$ is the additional growth resulting from the interaction of components $\mathrm{A}$ and $\mathrm{B}$ applied at rates $a$ and $b$, respectively (i.e., the outcome of component B acting on $\Delta \mathrm{G}_{\mathrm{A}}$ or vice versa). Therefore, the predicted growth resulting from a mixture of two active components, $G_{(A+B)}$, can be expressed as $\mathrm{G}_{(\mathrm{A}+\mathrm{B})}=\mathrm{G}_{\mathrm{CTL}}+\Delta \mathrm{G}_{(\mathrm{A}+\mathrm{B})}$. After reformatting, the predicted growth may be written as Eq. [1]:

$$
\mathrm{G}_{(\mathrm{A}+\mathrm{B})}=\mathrm{G}_{\mathrm{CTL}}+\Delta \mathrm{G}_{\mathrm{A}}+\Delta \mathrm{G}_{\mathrm{B}}+\Delta \mathrm{G}_{\mathrm{AB}}
$$

In Eq. [1], $\mathrm{G}_{\mathrm{CTL}}$ is the final measurement of growth for the control (e.g., final height, weight, or number), and $\Delta \mathrm{G}_{\mathrm{A}}$ can be calculated using the following:

$$
\Delta \mathrm{G}_{\mathrm{A}}=\mathrm{G}_{\mathrm{A}}-\mathrm{G}_{\mathrm{CTL}}
$$

where $G_{A}$ is the final measurement of growth resulting from component $A$ when applied alone at rate $a$. Similarly, $\Delta \mathrm{G}_{\mathrm{B}}$ can be calculated using the following:

$$
\Delta \mathrm{G}_{\mathrm{B}}=\mathrm{G}_{\mathrm{B}}-\mathrm{G}_{\mathrm{CTL}}
$$

where $G_{B}$ is the final measurement of growth resulting from component $\mathrm{B}$ when applied alone at rate $b$.

The $\Delta \mathrm{G}_{\mathrm{AB}}$ is the additional growth resulting from component $\mathrm{B}$ acting on $\Delta \mathrm{G}_{\mathrm{A}}$ (or vice versa); therefore, $\Delta \mathrm{G}_{\mathrm{AB}}$ can be expressed as $\Delta \mathrm{G}_{\mathrm{A}}\left(\Delta \mathrm{G}_{\mathrm{B}} / \mathrm{G}_{\mathrm{CTL}}\right)$, where $\left(\Delta \mathrm{G}_{\mathrm{B}} / \mathrm{G}_{\mathrm{CTL}}\right)$ is the effect of component $\mathrm{B}$ when acting alone at rate $b$ relative to the control. This expression can be further transformed to the following:

$$
\Delta \mathrm{G}_{\mathrm{AB}}=\left(\mathrm{G}_{\mathrm{A}}-\mathrm{G}_{\mathrm{CTL}}\right)\left(\mathrm{G}_{\mathrm{B}}-\mathrm{G}_{\mathrm{CTL}}\right) / \mathrm{G}_{\mathrm{CTL}}
$$

After substitution, Eq. [1] (predicted growth) is expressed as follows:

$$
\begin{aligned}
\mathrm{G}_{(\mathrm{A}+\mathrm{B})} & =\mathrm{G}_{\mathrm{CTL}}+\mathrm{G}_{\mathrm{A}}-\mathrm{G}_{\mathrm{CTL}}+\mathrm{G}_{\mathrm{B}}-\mathrm{G}_{\mathrm{CTL}} \\
& +\left(\mathrm{G}_{\mathrm{A}}-\mathrm{G}_{\mathrm{CTL}}\right)\left(\mathrm{G}_{\mathrm{B}}-\mathrm{G}_{\mathrm{CTL}}\right) / \mathrm{G}_{\mathrm{CTL}}
\end{aligned}
$$

which, after expansion, can be simplified to Eq. [2]:

$$
\begin{array}{r}
G_{(A+B)}=G_{C T L}+G_{A}-G_{C T L}+G_{B} \\
-G_{C T L}+\left(G_{A} G_{B}-G_{A} G_{C T L}\right.
\end{array}
$$

$$
\begin{gathered}
\left.-\mathrm{G}_{\mathrm{B}} \mathrm{G}_{\mathrm{CTL}}+\mathrm{G}_{\mathrm{CTL}}{ }^{2}\right) / \mathrm{G}_{\mathrm{CTL}} \\
=\mathrm{G}_{\mathrm{CTL}}+\mathrm{G}_{\mathrm{A}}-\mathrm{G}_{\mathrm{CTL}}+\mathrm{G}_{\mathrm{B}}-\mathrm{G}_{\mathrm{CTL}} \\
+\mathrm{G}_{\mathrm{A}} \mathrm{G}_{\mathrm{B}} / \mathrm{G}_{\mathrm{CTL}}-\mathrm{G}_{\mathrm{A}} \mathrm{G}_{\mathrm{CTL}} / \mathrm{G}_{\mathrm{CTL}}
\end{gathered}
$$$$
-\mathrm{G}_{\mathrm{B}} \mathrm{G}_{\mathrm{CTL}} / \mathrm{G}_{\mathrm{CTL}}+\mathrm{G}_{\mathrm{CTL}}{ }^{2} / \mathrm{G}_{\mathrm{CTL}}
$$$$
\mathrm{G}_{(\mathrm{A}+\mathrm{B})}=\mathrm{G}_{\mathrm{A}} \mathrm{G}_{\mathrm{B}} / \mathrm{G}_{\mathrm{CTL}}
$$

In Eq. [2], $G_{A}$ is the outcome caused by component $A$ and $G_{B} / G_{C T L}$ is the effect caused by component $\mathrm{B}$ when compared with the control; $G_{(A+B)}$ represents the predicted effect produced by component $\mathrm{B}$ acting on the resulting outcome of component A. This concept is embedded in the theory of Independent Joint Action (Finney, 1952; Kosman and Cohen, 1996).

The formula to compute the growth caused by a mixture of more than two components can be derived in a similar fashion (vide infra). For a mixture of three components, the mathematical model is written as follows:

$$
\begin{aligned}
& \Delta \mathrm{G}_{(\mathrm{A}+\mathrm{B}+\mathrm{C})}=\Delta \mathrm{G}_{\mathrm{A}}+\Delta \mathrm{G}_{\mathrm{B}}+\Delta \mathrm{G}_{\mathrm{C}} \\
& +\Delta \mathrm{G}_{\mathrm{AB}}+\Delta \mathrm{G}_{\mathrm{AC}}+\Delta \mathrm{G}_{\mathrm{BC}}+\Delta \mathrm{G}_{\mathrm{ABC}}
\end{aligned}
$$

The $\Delta \mathrm{G}_{(\mathrm{A}+\mathrm{B}+\mathrm{C})}$ is the difference in growth (when compared with the control) resulting from a three-component mixture containing components $\mathrm{A}, \mathrm{B}$, and $\mathrm{C}$ applied at rates $a, b$, and $c$, respectively. The $\Delta \mathrm{G}_{\mathrm{A}}$ is the difference in growth (when compared with the control) resulting from component A when applied alone. The $\Delta \mathrm{G}_{\mathrm{B}}$ is the difference in growth (when compared with the control) resulting from component $\mathrm{B}$ when applied alone. The $\Delta \mathrm{G}_{\mathrm{C}}$ is the difference in growth (when compared with the control) resulting from component $\mathrm{C}$ when applied alone at rates $a, b$, and $c$, respectively. The $\Delta \mathrm{G}_{\mathrm{AB}}, \Delta \mathrm{G}_{\mathrm{AC}}$, and $\Delta \mathrm{G}_{\mathrm{BC}}$ are the differences in growth resulting from the interaction of the two-component combinations described previously. The $\Delta \mathrm{G}_{\mathrm{ABC}}$ is the difference in growth resulting from the interaction of components $\mathrm{A}, \mathrm{B}$, and $\mathrm{C}$ and can be expressed as follows:

$$
\Delta \mathrm{G}_{\mathrm{ABC}}=\left(\mathrm{G}_{\mathrm{A}}-\mathrm{G}_{\mathrm{CTL}}\right)\left[\left(\mathrm{G}_{\mathrm{B}}-\mathrm{G}_{\mathrm{CTL}}\right) / \mathrm{G}_{\mathrm{CTL}}\right]
$$

$$
\left[\left(\mathrm{G}_{\mathrm{C}}-\mathrm{G}_{\mathrm{CTL}}\right) / \mathrm{G}_{\mathrm{CTL}}\right]
$$

Therefore, the following equation can be used to determine the predicted growth caused by a mixture of three active components, $\mathrm{G}_{(\mathrm{A}+\mathrm{B}+\mathrm{C})}$ :

$$
\begin{array}{r}
\mathrm{G}_{(\mathrm{A}+\mathrm{B}+\mathrm{C})}=\mathrm{G}_{\mathrm{CTL}}+\Delta \mathrm{G}_{\mathrm{A}}+\Delta \mathrm{G}_{\mathrm{B}}+\Delta \mathrm{G}_{\mathrm{C}} \\
+\Delta \mathrm{G}_{\mathrm{AB}}+\Delta \mathrm{G}_{\mathrm{AC}}+\Delta \mathrm{G}_{\mathrm{BC}}+\Delta \mathrm{G}_{\mathrm{ABC}}
\end{array}
$$

Similar to the method used to derive Eq. [2], this formula can be further transformed and simplified to the following:

$$
\mathrm{G}_{(\mathrm{A}+\mathrm{B}+\mathrm{C})}=\mathrm{G}_{\mathrm{A}} \mathrm{G}_{\mathrm{B}} \mathrm{G}_{\mathrm{C}} /\left(\mathrm{G}_{\mathrm{CTL}}\right)^{2}
$$

Rewriting the aforementioned formula as $\mathrm{G}_{(\mathrm{A}+\mathrm{B}+\mathrm{C})}=\mathrm{G}_{(\mathrm{A}+\mathrm{B})} \mathrm{G}_{\mathrm{C}} / \mathrm{G}_{\mathrm{CTL}}$ simplifies its interpretation because component $\mathrm{C}$ (when compared with the control), $\mathrm{G}_{\mathrm{C}} / \mathrm{G}_{\mathrm{CTL}}$, acting on the outcome resulting from components $\mathrm{A}$ and $\mathrm{B}, \mathrm{G}_{(\mathrm{A}+\mathrm{B})}$, is made visible in the equation. Theoretically, a generalized formula can be written as Eq. [3]:

$$
\mathrm{G}_{(1+2 \cdot \cdot n)}=\mathrm{G}_{1} \mathrm{G}_{2} \ldots \mathrm{G}_{n} /\left(\mathrm{G}_{\mathrm{CTL}}\right)^{n-1}
$$

where $n$ is the number of components in the mixture and $\mathrm{G}_{(1+2 . . n)}$ is the predicted growth resulting from the mixture of $n$ components.

Greenhouse corn seedling growth assay. An experiment was conducted to determine how gibberellin $\mathrm{A}_{4}\left(\mathrm{GA}_{4}\right)$ and $S$-ABA, applied as foliar spray treatments, affected the growth of maize plants (V3 growth stage) to demonstrate the use of Eq. [2] to predict the growth caused by the mixture. Three-quart, blow-molded pots were filled to capacity with Pro-Mix BX potting medium (Conserv FS, Wauconda, IL) that was mixed and uniformly amended with gypsum and controlled-release fertilizer granules. General purpose fertilizer solution containing 150 ppm nitrogen in the form of nitrate and ammonium was used to water the pots to saturation. Pioneer 32 T85 corn seeds were planted $5.7 \mathrm{~cm}$ deep in each saturated pot and sown in the greenhouse at $25^{\circ} \mathrm{C}$ with a $16: 8$ photoperiod and light intensity of $200 \mu \mathrm{mol} \cdot \mathrm{m}^{-2} \cdot \mathrm{s}^{-1}$. When plants reached the V3 growth stage, plant heights were measured to the nearest half-centimeter immediately before the application of plant growth regulators and $6 \mathrm{~d}$ after plant growth regulator application. Plant height was measured along the length of the shoot from the surface of the growing media to the tip of the tallest blade while plant blades were pulled tautly upward.

After the initial height measurements were recorded, plants were randomly divided into four groups with eight plants in each group. Each of the four groups was sprayed with one of four foliar treatments at an application rate of 30 gallons per acre (equivalent to $110 \mathrm{~L}$ per acre) via an automated track sprayer (Generation III Research Track Sprayer; DeVries Manufacturing, Hollandale, MN) to ensure consistent volume application and uniform plant coverage. The four treatments include a control, 8.9 ppm $S$-ABA, 114 ppm $\mathrm{GA}_{4}$, and the combination of $S-\mathrm{ABA}$ and $\mathrm{GA}_{4}$ at concentrations of $8.9 \mathrm{ppm}$ and 114 ppm, respectively. Technical powders for each compound were used to prepare treatment solutions. All treatment solutions contained deionized water and a nonionic surfactant at $0.25 \%(\mathrm{v} / \mathrm{v})$. The control was treated with $0.25 \%$ surfactant solution. After spraying, plants were randomly arranged in the greenhouse. The random arrangement of all plants was maintained in the same greenhouse location until final plant height data were collected. Growth measurements (i.e., the difference between the final height and 


\begin{tabular}{lcc}
\hline & \multicolumn{2}{c}{ Change in ht (growth), cm } \\
\cline { 2 - 3 } Treatment group (Eq. [2] variable) & Mean $^{\mathrm{z}}$ & $\mathrm{SE}$ \\
\hline Control $\left(\mathrm{G}_{\mathrm{CTL}}\right)$ & $30.25 \mathrm{a}$ & 1.0897 \\
$S$-ABA at $8.9 \mathrm{ppm}\left(\mathrm{G}_{\mathrm{A}}\right)$ & $30.56 \mathrm{a}$ & 0.6083 \\
$\mathrm{GA}_{4}$ at $114 \mathrm{ppm}\left(\mathrm{G}_{\mathrm{B}}\right)$ & $33.69 \mathrm{~b}$ & 0.6263 \\
$S$-ABA at $8.9 \mathrm{ppm}+\mathrm{GA}_{4}$ at $114 \mathrm{ppm}$ & $37.06 \mathrm{c}$ & 0.6244
\end{tabular}

the last 20 years. Environ. Toxicol. Chem. 32(8):1685-1687, doi: 10.1002/etc.2294.

Basra, A.S. 2000. Plant growth regulators in agriculture and horticulture: Their roles and commercial uses. Food Products Press, an imprint of The Haworth Press, Inc., New York.

Bliss, C.I. 1939. The toxicity of poisons applied jointly. Ann. Appl. Biol. 26:585-615, doi: 10.1111/j.1744-7348.1939.tb06990.x.

Cedergreen, N., C. Svendsen, and T. Backhaus. 2013. Chemical mixtures: Concepts for predicting toxicity, p. 2601-2610. In: S.E. Jorgensen (ed.). Encyclopedia of environmental management. Taylor \& Francis, New York.

initial height) for each individual plant were used for analysis.

Data analysis. A one-way analysis of variance (ANOVA) model and Tukey's honestly significant difference test were used to determine if significant growth differences existed between treatments. A one-sample, two-tailed Student's $t$ test was used to assess the difference between the predicted growth and the measured growth resulting from the mixture. If the difference between the measured growth and the predicted growth was not significant $(P \geq 0.05)$, then the mixture had an additive effect. If the measured growth was significantly greater than the predicted growth $(P<0.05)$, then the mixture had a synergistic effect. If the measured growth was significantly less than the predicted value $(P<0.05)$, then the mixture had a less-than-additive or antagonistic effect. Minitab (Minitab, LLC, State College, PA) was used for all statistical analyses.

\section{Results}

The ANOVA results indicated highly significant differences among treatments. Data regarding the corn seedling change in height (growth) and the standard error for each treatment are summarized in Table 1.

Eq. [2], $\mathrm{G}_{(\mathrm{A}+\mathrm{B})}=\mathrm{G}_{\mathrm{A}} \mathrm{G}_{\mathrm{B}} / \mathrm{G}_{\mathrm{CTL}}$, was used to compute the predicted growth caused by the mixture. The predicted growth value of $34.04 \mathrm{~cm}$ was then used in a one-sample, two-tailed Student's $t$ test. The measured change in height (growth) caused by the mixture, 37.06 (Table 1), was significantly greater than the predicted change in height (growth) $(P<0.01)$. Consequently, it can be concluded that the mixture of $S$-ABA and $\mathrm{GA}_{4}$ at the tested ratio has a synergistic effect on shoot growth.

\section{Discussion}

As demonstrated, the proposed Eq. [2] extends the application of Bliss's Independent Joint Action theory to effects on growth. In Bliss's formula, $\mathrm{P}_{(\mathrm{A}+\mathrm{B})}=\mathrm{P}_{\mathrm{A}}+$ $\mathrm{P}_{\mathrm{B}}-\mathrm{P}_{\mathrm{A}} \mathrm{P}_{\mathrm{B}}$, the mortality caused by both components acting together, $\mathrm{P}_{\mathrm{A}} \mathrm{P}_{\mathrm{B}}$, is subsequently subtracted; this is because when an insect is killed by one component, it cannot be killed again by a second component. Furthermore, the effect on growth produced by components acting together in a mixture, i.e., $\Delta \mathrm{G}_{\mathrm{AB}}$ in the model for growth (Eq.
[2]), is an addition to a resulting effect. Therefore, using Eq. [2] is conceptually suitable for computing predicted growth effects.

Eq. [2] is also able to accommodate the percent growth or inhibition data (e.g., mortality/lethality for which the Independent Joint Action theory and Bliss's formula were originally established). For example, when growth caused by treatments are expressed as (or transformed to) percent of control, where the control is equivalent to $100 \%$, Eq. [2] can compute the predicted growth (expressed as a percent of control) after it has been transformed to the following:

$$
\mathrm{G}_{(\mathrm{A}+\mathrm{B})}^{\prime}=\mathrm{G}_{\mathrm{A}}^{\prime} \mathrm{G}_{\mathrm{B}}^{\prime} / 100
$$

where $G_{(A+B)}^{\prime}$ represents the predicted growth percent of the control for the mixture, the number 100 denotes the base value of the control, and $\mathrm{G}_{\mathrm{A}}^{\prime}$ and $\mathrm{G}_{\mathrm{B}}^{\prime}$ represent the percent of the control resulting from treatment with components $\mathrm{A}$ and $\mathrm{B}$, respectively. This matches the formula Colby had proposed after deriving it from Bliss's formula as an alternative approach to predict the percent inhibition of herbicide mixtures (Colby, 1967). This establishes a link connecting Eq. [2] to Bliss and Colby's formulas, whereby Eq. [2] can accommodate both the percent of control data and other data types (e.g., direct values) more readily.

The generalized formula, Eq. [3], is potentially applicable to studies that include combinations of various physical or chemical factors influencing both the promotion and inhibition of growth such as environmental factors (i.e., light intensity, temperature), agrochemicals, microbials, and antibiotics or other medicinal drugs, in addition to plant growth regulators. The $S$-ABA/GA 4 mixture greenhouse data were used exclusively for the purpose of demonstrating how to properly apply the proposed Eq. [2] to assess synergy. The synergy of this mixture requires more studies for further confirmation.

\section{Literature Cited}

Abbott, W.S. 1925. A method of computing the effectiveness of an insecticide. J. Econ. Entomol. 18:265-267, doi: 10.1093/jee/18.2.265a.

Altenburger, R., T. Backhaus, W. Boedeker, M. Faust, and M. Scholze. 2013. Simplifying complexity: Mixture toxicity assessment in
Cedergreen, N., C. Svendsen, and T. Backhaus. 2014. Quantifying synergy: A systematic review of mixture toxicity studies within environmental toxicology. PLoS One 9(5):e96580, doi: 10.1371/journal.pone.0096580.

Chou, T.C. 2006. Theoretical basis, experimental design, and computerized simulation of synergism and antagonism in drug combination studies. Pharmacol. Rev. 58:621-681, doi: 10.1124 pr.58.3.10.

Colby, S.R. 1967. Calculating synergistic and antagonistic responses of herbicide concentrations. Weeds 15(1):20-22, doi: 10.2307/ 4041058.

Finney, D.J. 1952. An introduction to statistical science in agriculture. John Wiley \& Sons, New York, doi: 10.2136/sssaj1953.03615995001700030032x.

Fletcher, R.A., C.R. Sopher, and N.N. Vettakkorumakank. 2000. Regulation of gibberellins is crucial for plant stress protection, p. 71-87. In: A.S. Basra (ed.). Plant growth regulators in agriculture and horticulture-their roles and commercial uses. Food Products Press, an imprint of The Haworth Press, Inc., New York.

Foucquier, J. and M. Guedj. 2015. Analysis of drug combinations: Current methodological landscape. Pharmacol. Res. Perspect. 3(3): e00149, doi: 10.1002/prp2.149.

Gisi, U. 1989. Synergism between fungicides for control of phytophthora, p. 361-372. In: J.A. Lucas, R.C. Shattock, D.S. Shaw, and L.R. Cooke (eds.). Phytophthora. Cambridge University Press, Cambridge.

Gisi, U. 1996. Synergistic interaction of fungicides in mixtures. Phytopathology 86(11):1273-1279.

Kaur, P., D. Mal, A. Sheokand, L. Singh, and D. Datta. 2018. Role of plant growth regulators in vegetable production: A review. Intl. J. Curr. Microbiol. Appl. Sci. 7(06):2177-2183, doi: 10.20546/ijcmas.2018.706.258.

Kosman, E. and Y. Cohen. 1996. Procedures for calculating and differentiating synergism and antagonism in action of fungicide mixtures. Phytopathology 86(11):1263-1272.

Kull, F.C., P.C. Eisman, H.D. Sylwestrowicz, and R.L. Mayer. 1961. Mixtures of quaternary ammonium compounds and long-chain fatty acids as antifungal agents. Appl. Environ. Microbiol. 9:538-541.

Levy, Y., M. Benderly, Y. Cohen, U. Gisi, and D. Bassand. 1986. The joint action of fungicides in mixtures: Comparison of two methods for synergy calculation. Bull. OEPP 16(4):651-657, doi: 10.1111/j.1365-2338.1986.tb00338.x.

Loewe, S. and H. Muischnek. 1926. Über kombinationswirkungen. 1. Mitteilung: Hilfsmittel der Fragestellung. Naunyn Schmiedebergs Arch. Exp. Pathol. Pharmakol. 114:313-326.

Morse, P.M. 1978. Some comments on the assessment of Joint Action in herbicide mixtures. Weed Sci. 26(1):58-71.

Nash, R.G. 1981. Phytotoxic interaction studiestechniques for evaluation and presentation of 
results. Weed Sci. 29(2):147-155, doi: 10. Tammes, P.M.L. 1964. Isoboles, a graphic repre1017/S0043174500061701.

Pohanish, R. 2014. Sittig's handbook of pesticides and agricultural chemicals. 2nd ed. William Andrew Publishing, an imprint of Elsevier Inc., New York.

Roell, K.R., D.M. Reif, and A.A. Motsinger-Reif. 2017. An introduction to terminology and methodology of chemical synergy - perspectives from across disciplines. Front. Pharmacol. 8:158, doi: 10.3389/fphar.2017.00158. sentation of synergism in pesticides. Neth. J. Plant Pathol. 70:73-80, doi: 10.1007/ BF01974412.

U.S. Environmental Protection Agency. 2000. Supplementary guidance for conducting health risk assessment of chemical mixtures, Risk Assessment Forum, Washingtion, DC.

Voorspuij, Z.A. and C. Nass. 1957. Some aspects in the simultaneous activity of two antibacterial agents in vitro. Arch. Intern. Pharmacodynamie 109:211-228.

Zhao, L., J.L.S. Au, and M.G. Wientje. 2010. Comparison of methods for evaluating drug-drug interaction. Front. Biosci. (Elite Ed.) 2:241-249.

Zhao, W., K. Sachsenmeier, L. Zhang, E. Sult, R.E. Hollingsworth, and H. Yang. 2014. A new Bliss Independence Model to analyze drug combination data. J. Biomol. Screen. 19(5):817-821, doi: $10.1177 / 1087057114521867$. 